\title{
Safety, tolerability and pharmacokinetics of
}

\section{udenafil, a novel PDE-5 inhibitor, in healthy young Korean subjects}

\section{Bo-Hyung Kim, Hyeong-Seok Lim, ${ }^{1}$ Jae-Yong Chung, Jung-Ryul Kim,} Kyoung Soo Lim, Dong-Ryul Sohn, ${ }^{2}$ Joo-Youn Cho, Kyung-Sang Yu, Sang-Goo Shin, Jae-Seung Paick ${ }^{3} \&$ In-Jin Jang

Departments of Pharmacology and Clinical Pharmacology Unit and ${ }^{3}$ Urology, Seoul National University College of Medicine and Hospital, ${ }^{1}$ Department of Clinical Pharmacology and Therapeutics, Ulsan University College of Medicine and Asan Medical Centre and ${ }^{2}$ Department of Clinical Pharmacology, Soonchunhyang University College of Medicine, Seoul, Korea

\section{Correspondence}

Professor In-Jin Jang, MD, PhD,

Department of Pharmacology and Clinical Pharmacology Unit, Seoul National University College of Medicine and Hospital, Seoul, Republic of Korea, 28 Yongon-dong, Jongno-gu, Seoul 110-744, Korea.

Tel: +8227408290

Fax: + 8227457996

E-mail: ijjang@snu.ac.kr

The investigational site: Clinical Trials Centre, Seoul National University Hospital.

\section{Keywords}

pharmacokinetics, phosphodiesterase type 5 inhibitor, safety, udenafil

\section{Received}

18 October 2007

Accepted

20 December 2007

Published OnlineEarly

3 March 2008

\section{WHAT IS ALREADY KNOWN ABOUT} THIS SUBJECT

-The phosphodiesterase (PDE) type 5 inhibitor is a widely used agent that facilitates penile erection. - Udenafil is newly developed as a PDE-5 inhibitor.

\section{WHAT THIS STUDY ADDS}

- This is the first study to determine the safety, tolerability and pharmacokinetics of udenafil in healthy subjects.

- Udenafil was safe and well tolerated in healthy Korean subjects.

- The AUC and $C_{\max }$ of udenafil increased supraproportionally with increasing dose upon single administration, but there was no significant drug accumulation upon multiple administrations.

\section{AIM}

To evaluate the safety, tolerability and pharmacokinetics (PK) of udenafil, a novel phosphodiesterase type 5 inhibitor.

\section{METHODS}

A double-blind, randomized, placebo-controlled, dose-rising, parallel-group, single- and multiple-dose study was conducted in healthy Korean subjects. The subjects were allocated to single-dose groups of 25,50,100, 200 or $300 \mathrm{mg}$ (eight subjects in each dose group, including two placebos), or to multiple-dose groups of 100 or 200 mg (once-daily dosing for 7 days; nine subjects in each dose group, including three placebos). Serial samples of blood and urine were collected after oral administration and the drug concentrations in plasma and urine were determined by high-performance liquid chromatography. Safety and tolerability were evaluated by monitoring clinical laboratory parameters and adverse events.

\section{RESULTS}

Udenafil reached peak plasma concentrations at $0.8-1.3 \mathrm{~h}$, and then declined mono-exponentially with a terminal half-life of $7.3-12.1 \mathrm{~h}$ in the single-dose study. The area under the time-concentration curves (AUC) and maximum plasma concentrations $\left(C_{\max }\right)$ increased supraproportionally with increasing dose in the single-dose study. During multiple dosing, a steady state was reached at 5 days and little accumulation occurred after repeated dosing for 7 days. Udenafil was generally well tolerated in these healthy subjects, and no serious adverse events occurred.

\section{CONCLUSIONS}

Udenafil was safe and well tolerated in healthy volunteers. The AUC and $C_{\max }$ of udenafil increased supraproportionally with increasing dose upon single administration, but there was no significant drug accumulation upon multiple administrations. 


\section{Introduction}

Approximately $20 \%$ of males $>20$ years old in the USA are reported to have experienced erectile dysfunction and its incidence increases with age [1]. As the prevalence of diabetes and cardiovascular disease increases, the incidence of erectile dysfunction also increases.

Nitric oxide is locally released during sexual stimulation and activates guanylate cyclase, which increases guanosine $3^{\prime}, 5^{\prime}$-cyclic monophosphate (cGMP). This in turn relaxes the smooth muscles in the corpus cavernosum and induces blood inflow, resulting in penile erection $[2,3]$. Phosphodiesterase type 5 (PDE-5) predominates in the corpus cavernosum and ends penile erection by disintegrating cGMP [4]. Thus, the inhibition of PDE-5 maintains a penile erection which has been induced by sexual stimulation.

PDE-5 inhibitors are widely used for the treatment of erectile dysfunction. However, PDE-5 inhibitors exhibit adverse reactions such as facial flushing, headache, colour discrimination abnormality, cardiovascular events and so on $[5,6]$. PDE-5 is distributed throughout the systemic vasculature, although it is principally found in the corpus cavernosum and lung [7]. Therefore, increased cGMP by a PDE-5 inhibitor in the systemic vasculature may induce vasodilation and subsequent decrease in blood pressure [8]. It has been a major concern that PDE-5 inhibitors may increase the risk of cardiovascular events, especially in patients taking concomitant nitrates for comorbid vascular diseases [9]. Thus, efforts are underway to develop new PDE-5 inhibitors having a higher potency, but with a lower incidence of adverse drug reactions.

Udenafil (5-[2-propyloxy-5-(1-methyl-2-pyrollidiny lethylamidosulphonyl)phenhyl] - 1 - methyl-3-propyl-1,6dihydro-7H-pyrazolo(4,3-d)-pyrimidin-7-one; Zydena ${ }^{\circledR}$, Dong-A Pharmaceutical Company, Seoul, S. Korea) is a novel, potent PDE-5 inhibitor having a similar molecular structure to sildenafil citrate (Viagra ${ }^{\circledR}$ ) (Figure 1) [10]. An in vitro study evaluating various PDE isozymes has shown that udenafil is comparable to sildenafil $\left(\right.$ Viagra $\left.^{\circledR}\right)$ in selectivity to PDE-5 [11]. It has been shown to have potent erectogenic properties in rats and rabbits with a broad safety margin in preclinical studies [12].

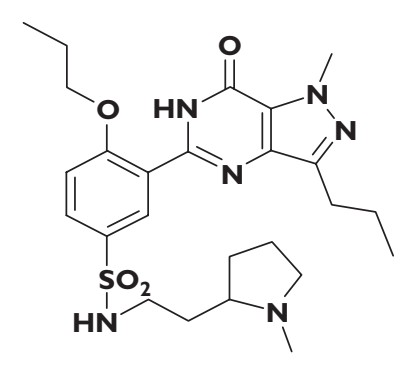

\section{Figure 1}

Chemical structure of udenafil
As a first-in-human clinical trial, this study was conducted to evaluate the safety, tolerability and pharmacokinetic (PK) characteristics after single and multiple oral administrations in healthy male subjects.

\section{Methods}

The study was conducted at the Clinical Trials Centre, Seoul National University Hospital (SNUH) and the study protocol was approved by the Institutional Review Board of SNUH. All procedures were performed in accordance with the recommendations of the Declaration of Helsinki on biomedical research involving human subjects. All subjects gave written informed consent before being enrolled.

\section{Study population}

Forty male subjects, aged 19-32 years (mean \pm SD: $23.5 \pm$ 3.5 years) and weighing $51.4-81.0 \mathrm{~kg}(65.9 \pm 7.3 \mathrm{~kg})$, participated in the single-dose study, and 18 healthy male subjects, aged $20-29$ years ( $24.1 \pm 2.9$ years) and weighing $60.0-76.7 \mathrm{~kg}(67.1 \pm 5.2 \mathrm{~kg})$, took part in the multiple-dose study. The subjects were evaluated as being healthy by physical examination, vital signs, 12-lead electrocardiography (ECG), serology, urinary drug screen, routine clinical laboratory tests, visual acuity test and colour discrimination test performed within 3 weeks of the first administration of the study drug. All subjects with a history of achromatopsia, dyschromatopsia or retinitis pigmentosa were excluded from the study. Subjects were prohibited from the use of any drugs within 7 days prior to the study, including heavy drinking. Additionally, their body weight was required to be within $85-115 \%$ of ideal body weight. Subjects were required also not to have smoked within 3 months of the first administration of the study drug.

\section{Study design}

This study was conducted as a double-blind, randomized, placebo-controlled, dose-escalating, parallel-group design. In the single-dose study, subjects were randomly assigned to one of five dosage groups of 25, 50, 100, 200 or $300 \mathrm{mg}$; each group contained eight subjects, two of whom were were randomly allocated to receive placebo. The subjects were admitted in the morning of day -1 ( 1 day before study drug administration) for baseline evaluations. On the next day (day 1 ), the subjects were orally administered the scheduled dosage with $240 \mathrm{ml}$ of water around $09.00 \mathrm{~h}$, after an overnight fasting of at least $10 \mathrm{~h}$. They were kept in the semi-Fowler position and fasting state until $4 \mathrm{~h}$ after drug administration, except for $200 \mathrm{ml}$ of water $2 \mathrm{~h}$ after dosing. Subjects were discharged in the morning of day 2 and revisited for post-treatment evaluation on day 10 or 11 .

The multiple-dose study was performed after the single-dose study. Subjects were randomly assigned to one of two dose groups of 100 and $200 \mathrm{mg}$; each group contained nine subjects, three of whom received placebo. The 
subjects went through an identical schedule to that of the single-dose study for day -1 and 1 . From day 2 through day 7 , subjects were administered udenafil or placebo once a day at the same time as day 1 with $240 \mathrm{ml}$ of water. On day 7 , the subjects were given the drug after overnight fasting and were then kept in the semi-Fowler position and fasting state until $4 \mathrm{~h}$ after drug administration except for $200 \mathrm{ml}$ of water $2 \mathrm{~h}$ after dosing. The subjects were discharged on the morning of day 8 and revisited for post-treatment evaluation on day 16 or 17 .

For $48 \mathrm{~h}$ prior to day -1 and throughout the study, subjects were not allowed to consume drinks or beverages containing alcohol or caffeine.

\section{Safety and tolerability assessments}

The presence of adverse events was assessed at the end of each evaluation period by asking general health-related questions. Because visual disturbances were reported with previous PDE-5 inhibitors, visual acuity and colour discrimination tests (Farnsworth-Munsell 100-Hue test; http://www.munsell.eu/html/colour_vision_tests.html) were conducted before and after dosing. Physical examinations, 12-lead ECGs, routine laboratory parameters (clinical chemistry, haematology and urinalysis), platelet aggregation test and bleeding time were performed at predefined regular intervals throughout the studies. Semen was also evaluated to determine semen volume, sperm motility, sperm count and morphology prior to dosing (day -1) and on day 5 in the multiple-dose study. To evaluate the haemodynamic changes after the administration of udenafil, vital signs in the sitting position were measured before dosing and at regular intervals after dosing, and ambulatory blood pressure (ABP) and total peripheral resistance (TPR) were measured using an $A B P$ Monitor (SpaceLabs Inc., Issaquah, WA, USA) and computerized impedance cardiography (CIC-1000; Sorba Medical System, Milwaukee, WI, USA), respectively, before and after dosing at scheduled times.

\section{Pharmacokinetic evaluation}

Blood samples $(8 \mathrm{ml})$ were taken from an indwelling cannula inserted into a forearm vein at the scheduled times: before dosing $(0 \mathrm{~h}), 0.5,1,1.5,2,2.5,3,4,5,6,8,12,24$ and $32 \mathrm{~h}$ after drug administration during the single-dose study. For the multiple-dose study, blood samples were taken before and at $0.5,1,1.5,2,2.5,3,4,5,6,8,12$ and $24 \mathrm{~h}$ after dosing on day 1 , just before dosing on days 5,6 and 7 , and also at $0.5,1,1.5,2,2.5,3,4,5,6,8,12,24,32$ and $48 \mathrm{~h}$ after dosing on day 7 .

The blood samples were centrifuged at $1200 \mathrm{~g}$ for $10 \mathrm{~min}$ at $4^{\circ} \mathrm{C}$, and plasma was immediately stored in polypropylene tubes at $-20^{\circ} \mathrm{C}$ or less until measurement of the plasma concentrations of udenafil.

Urine samples were collected at predefined intervals of $0-8,8-24,24-32$ and $32-48 \mathrm{~h}$ after dosing in the singledose study. Urine was also collected from 0 to $12 \mathrm{~h}$ on day
1, and $0-12,12-24$ and $24-48 \mathrm{~h}$ after dosing on day 7 in the multiple-dose study.

Concentrations of udenafil were measured using plasma and urine samples. Noncompartmental PK analysis was performed using WinNonlin (Professional Network Version 5.0; Pharsight Corp., Mountain View, CA, USA). The actual blood collection times were used in PK analysis. The maximum drug concentrations in plasma $\left(C_{\max }\right)$ and the time at $C_{\max }\left(t_{\max }\right)$ were determined directly from the observed values. The terminal elimination rate constant $\left(\lambda_{z}\right)$ was estimated by linear regression of the log-linear decline of individual plasma concentration-time data. The terminal half-life $\left(t_{1 / 2}\right)$ was calculated for each individual as follows: $t_{1 / 2}=\ln (2) \lambda_{z}^{-1}$.

The individual area under the time-concentration curve (AUC) from time 0 to the last measurable time $\left(A \cup C_{\text {last }}\right)$ was calculated using the linear trapezoidal rule and the AUC extrapolated to infinity $\left(A \cup C_{\infty}\right.$ ) was calculated as follows: $A \cup C_{\infty}=A \cup C_{\text {last }}+C_{\text {last }} \lambda_{z}^{-1}\left(C_{\text {last }}\right.$ the last measurable concentration). Apparent clearance (CL/F) was calculated as Dose/AUC $C_{\infty}$. The individual renal clearance $\left(\mathrm{CL}_{R}\right)$ was calculated as follows: $\mathrm{CL}_{R}=A e_{0-48 \mathrm{~h}}$ (amount excreted in urine during $0-48 \mathrm{~h}$ ) $/ \mathrm{AUC}_{0-48 \mathrm{~h}}$ (AUC from 0 to $48 \mathrm{~h}$ ). The accumulation index $\left(R_{\text {ac }}\right)$ was calculated as $A \cup C_{\tau, \text { ss }}$ (day 7 , from 144 to $168 \mathrm{~h}$ ) $/ \mathrm{AUC}_{\tau}$ (day 1 , from 0 to $24 \mathrm{~h}$ ) in the multiple-dose study.

\section{Measurement of drug concentrations}

Udenafil concentrations in plasma and urine were determined using high-performance liquid chromatography, as described previously, with a slight modification [13]. Udenafil and the internal standard, sildenafil, were provided by the Dong-A Pharmaceutical Company. In brief, after vortexing the mixture of biological samples $(1 \mathrm{ml}$; urine was diluted 10-50 times), internal standard ( $250 \mathrm{ng}$ ), methanol $(100 \mu \mathrm{l})$, sodium bicarbonate buffer $(200 \mu \mathrm{l}$, $0.1 \mathrm{M})$ and ethyl ether $(5 \mathrm{ml})$ for $60 \mathrm{~s}$ and centrifuging at $3000 \mathrm{~g}$ for $10 \mathrm{~min}$, the organic layer was transferred and evaporated. The residue obtained was reconstituted in $150 \mu \mathrm{l}$ of the mobile phase and $100 \mu \mathrm{l}$ of the supernatant was injected onto a Capcell pak $\mathrm{C}_{18}$ column ( $5 \mu \mathrm{m}$ particle size, $150 \times 4.6 \mathrm{~mm}$ i.d.; Shiseido, Tokyo, Japan) at ambient temperature. The mobile phase consisted of acetonitrile (30\%) and $20 \mathrm{mM}$ potassium phosphate buffer of $\mathrm{pH} 4.5$ $(70 \%)$, which was delivered isocratically at a flow rate of $1.0 \mathrm{ml} \mathrm{min}{ }^{-1}$. Retention times for udenafil and the internal standard were approximately 12 and $9 \mathrm{~min}$, respectively. The peaks were determined using an ultraviolet detector set at a wavelength of $292 \mathrm{~nm}$. The lower limit of quantification was $5 \mathrm{ng} \mathrm{ml}^{-1}$ in plasma and $10 \mathrm{ng} \mathrm{ml}^{-1}$ in urine. The method was validated over the range $5-1000 \mathrm{ng} \mathrm{ml}^{-1}$ in plasma and $10-1000 \mathrm{ng} \mathrm{ml}^{-1}$ in urine. The accuracy in plasma for the within- and between-run ranged from $-12.9 \%$ to $2.2 \%$ and from $-10.0 \%$ to $-1.6 \%$, respectively, and the precision for the within- and between-run ranged from $0.8 \%$ to $5.1 \%$ and from $1.4 \%$ to $7.9 \%$, respectively. The 
accuracy in urine for the within- and between-run ranged from $-9.1 \%$ to $1.4 \%$ and from $-3.5 \%$ to $4.1 \%$, respectively, and the precision for the within- and between-run ranged from $1.3 \%$ to $3.3 \%$ and from $2.4 \%$ to $3.5 \%$, respectively [14].

\section{Statistical analysis}

All statistical analyses were performed using SPSS ${ }^{\circledR} 12.0$ software (SPSS Korea, Seoul, Korea). ANOVA was also used to evaluate any differences in apparent clearance $(C L / F)$, terminal half-life $\left(t_{1 / 2}\right)$ and renal clearance $\left(\mathrm{CL}_{R}\right)$ among the dose groups in the single-dose study. Dose linearity was also evaluated by comparing PK results such as $C_{\max } /$ dose and $A U C_{\infty} /$ dose in the single-dose study. In the multipledose study, PK results were compared to determine any differences between day 1 and day 7. In order to confirm the steady state of udenafil, predosing concentrations of udenafil on days 5 and 6 were compared using paired $t$-test. $P$-values $<0.05$ were considered to be statistically significant.

\section{Results}

\section{Safety and tolerability}

In the single-dose study, there were a total of 75 adverse events (AE). Of these, 71 were mild and four were moderate in severity. Forty-two AEs (56\%) were judged to be possibly related to udenafil and the frequency increased with the doses ( 0 cases in the $25-\mathrm{mg}$, three in the $50-\mathrm{mg}$, six in the 100-mg, 13 in the 200-mg and 20 in the $300-\mathrm{mg}$ dose group). The remaining $33 \mathrm{AEs}$ were decided to be possibly related to placebo (six cases, $8 \%$ ) or unrelated to udenafil or placebo (27 cases, 36\%). The common AEs which could be possibly related to udenafil were headache, penile erection, facial flushing (Table 1). Although penile erection would be an intended effect in erectile dysfunction patients, this symptom was classified as an AE in this study, considering that this was a first-in-human study in healthy subjects.

In the multiple-dose study, there were a total of 101 AEs. Of these, 94 were mild and seven AEs were moderate in severity. With regard to the relationship to udenafil, $82 \mathrm{AEs}$ (81\%) were determined to be possibly related to udenafil ( 29 cases in the 100-mg dose group, 53 cases in the 200-mg dose group). The remaining $19 \mathrm{AEs}$ were possibly related to placebo (six cases, $6 \%$ ) or unrelated to udenafil or placebo (13 cases, 13\%). The common AEs that could be possibly related to udenafil were headache, penile erection, facial flushing and febrile sensation (Table 1). The colour discrimination abnormality was detected in the multiple-dose study, which was related to the 'blue-green' region of the spectrum; it was detected $1.5 \mathrm{~h}$ after the first dosing on colour discrimination test and it spontaneously recovered to normal on the successive test $(1.5 \mathrm{~h}$ after the fourth dosing) (Table 1). Therefore, this abnormality was considered to be clinically insignificant.

There were no clinically significant findings in the routine laboratory parameters, visual acuity, platelet aggre-

\section{Table 1}

Number of possible treatment-related adverse events at each dose level

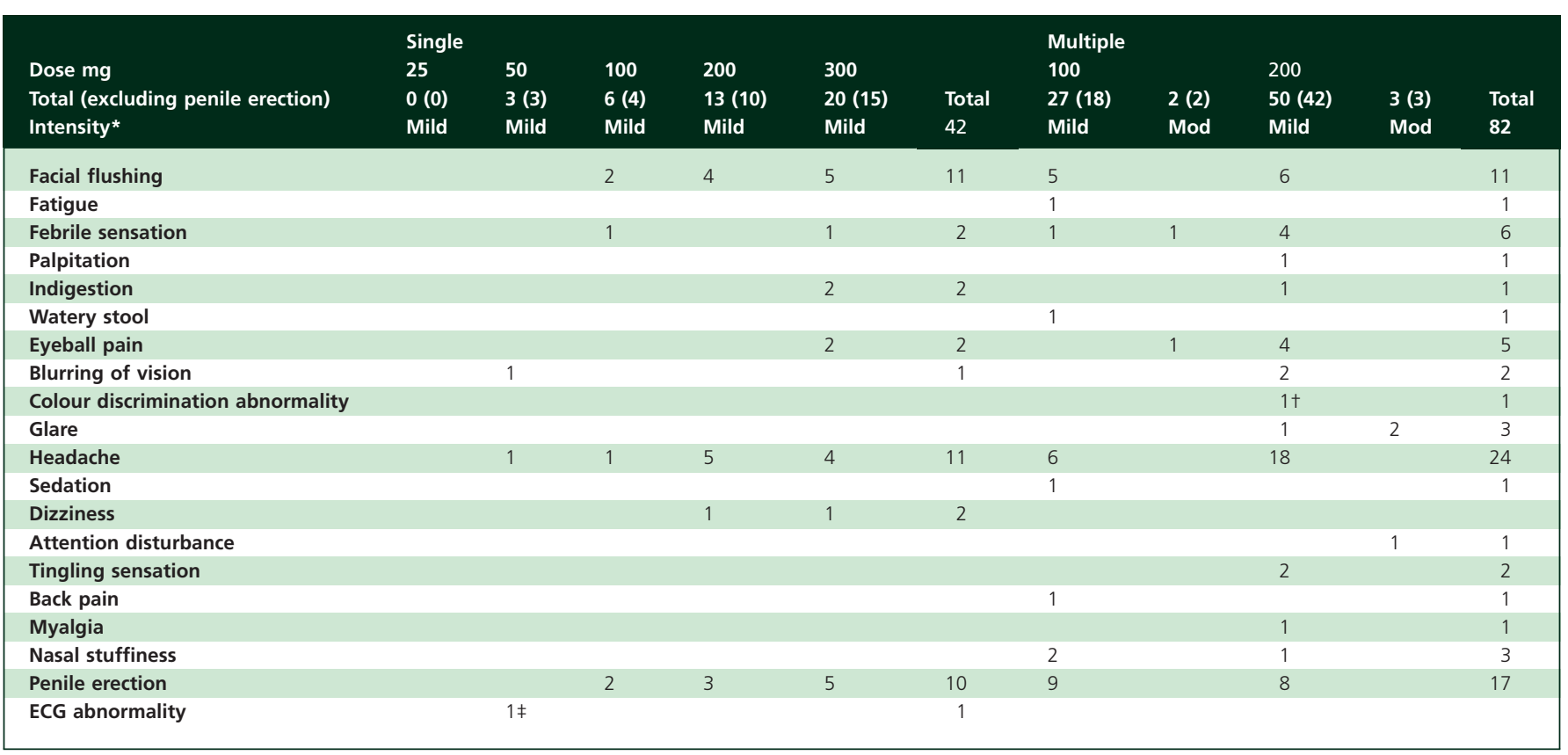

*Mod, moderate; there were no adverse events of 'moderate' or 'severe' intensity in the single-dose study, and no adverse events of 'severe' intensity in the multiple-dose study. †The 'blue-green' region abnormality on colour discrimination test was detected $1.5 \mathrm{~h}$ after the first dosing. $\neq$ These abnormalities (P-axis deviation, ectopic atrial rhythm) were detected $1 \mathrm{~h}$ after udenafil oral administration and then spontaneously recovered to normal $31 \mathrm{~h}$ later. 
gation test, bleeding time or semen analysis. Additionally, vital signs (sitting posture), ABP and TPR between the udenafil group and placebo group exhibited little difference, indicating there were no clinically significant changes (data not shown).

\section{Pharmacokinetic profile}

Udenafil was rapidly absorbed, reaching peak plasma concentrations at $0.8-1.3 \mathrm{~h}$ and then declining monoexponentially with a terminal half-life $\left(t_{1 / 2}\right)$ from 7.3 to $12.1 \mathrm{~h}$ in the single-dose group (Figure 2, Table 2). Significant differences were found in the apparent clearance $(\mathrm{CL} / F)$ and terminal half-life among the dosage groups $(P<0.05$ for ANOVA, Table 2). Similarly, there were significant differences in the dose-normalized $C_{\max }$ and $A \cup C_{\infty}$ among the dosage groups $(P<0.0001, A N O V A)$; both values increased on dose escalation. Therefore, the $C_{\max }$ and $A \cup C_{\infty}$
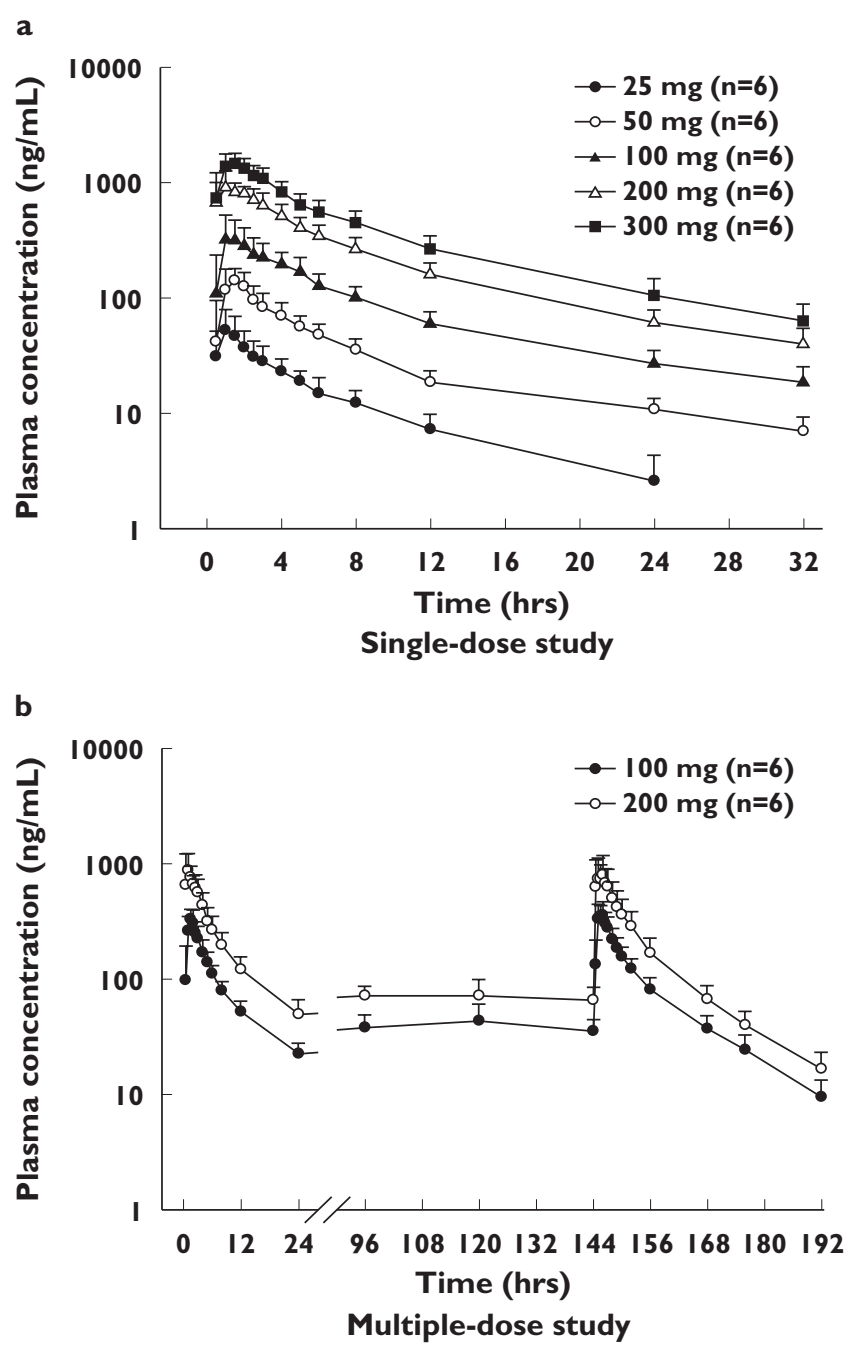

\section{Figure 2}

Mean plasma concentration-time profiles of udenafil after single or multiple oral administrations. Data are expressed as the mean \pm SD (each group, $n=6$ ) of udenafil increased supraproportionally with increasing dose (Figure 3), whereas the renal clearances $\left(\mathrm{CL}_{R}\right)$ were similar among the dosage groups.

In the multiple-dose study, inspection of the mean concentration-time profiles showed that udenafil reached steady state by day 5 . This was confirmed by using paired $t$-test between the dose-normalized concentration on day 5 and that on day $6 \quad(P=0.367$, Figure 2$)$. The concentration-time profiles on day 7 were comparable to those of day 1 (Figure 2). Pharmacokinetic parameters exhibited similar individual values for $C_{\max }$ and $t_{\max }$ between day 1 and day 7 (Table 2). Between the 100-mg and 200-mg dosage groups, no statistically significant differences were found in the dose-normalized $C_{\max }(P=$ $0.172)$ or dose-normalized $A \cup C_{\infty}$ on day $7(P=0.681, t$-test). However, the apparent clearance decreased in both the $100-\mathrm{mg}$ and 200-mg dosage groups on day 7 in comparison with day 1 , and, in contrast, the terminal half-life significantly increased on day 7 in comparison with day 1 $(P<0.05$ for paired $t$-test, Table 2$)$. The observed accumulation index was $1.39 \pm 0.26$ in the 100-mg and $1.22 \pm 0.20$ in the 200-mg dose group.

\section{Discussion}

In this first-in-human study of udenafil in healthy male subjects, there were dose-dependent increases in AEs across treatments. However, none of the AEs was severe, and all spontaneously disappeared without any treatment. Headache, facial flushing and nasal stuffiness were frequently reported, and these AEs have also been reported for other PDE-5 inhibitors, which are pharmacologically associated with vasodilation [6]. In addition, some subjects complained of eyeball pain, which has also been found in other PDE-5 inhibitors [10]. In the multiple-dose study, a 'blue-green' region abnormality on colour discrimination test was detected $1.5 \mathrm{~h}$ after the first dosing. The abnormality on the test spontaneously recovered to normal on successive tests ( $1.5 \mathrm{~h}$ after the fourth dosing). This transient impairment of colour discrimination (blue/green) has also been reported for the other PDE-5 inhibitors [10]. In addition, vital signs (sitting posture), ABP and TPR between the udenafil and placebo groups exhibited little difference, indicating there were no clinically significant changes. Although this result suggests that udenafil can be safely prescribed, it has the limitation that it was obtained only in normotensive subjects and needs to be further evaluated in patients in a variety of clinical situations.

The noncompartmental pharmacokinetic analysis in healthy subjects indicated increments of dose-normalized AUC and $C_{\max }$ in relation to dose in the single-dose study. In udenafil, $C_{\max }$ was increased to 2.7-fold, and $A U C_{\infty}$ was increased to 2.8 -fold (100- vs. 200-mg dose group). The $C_{\max }$ and $A U C_{\infty}$ of sildenafil were increased to 2.2- and 2.1-fold, respectively, on doubling of the dose based on regression 


\section{Table 2}

Pharmacokinetic parameters of udenafil following single and multiple oral administration

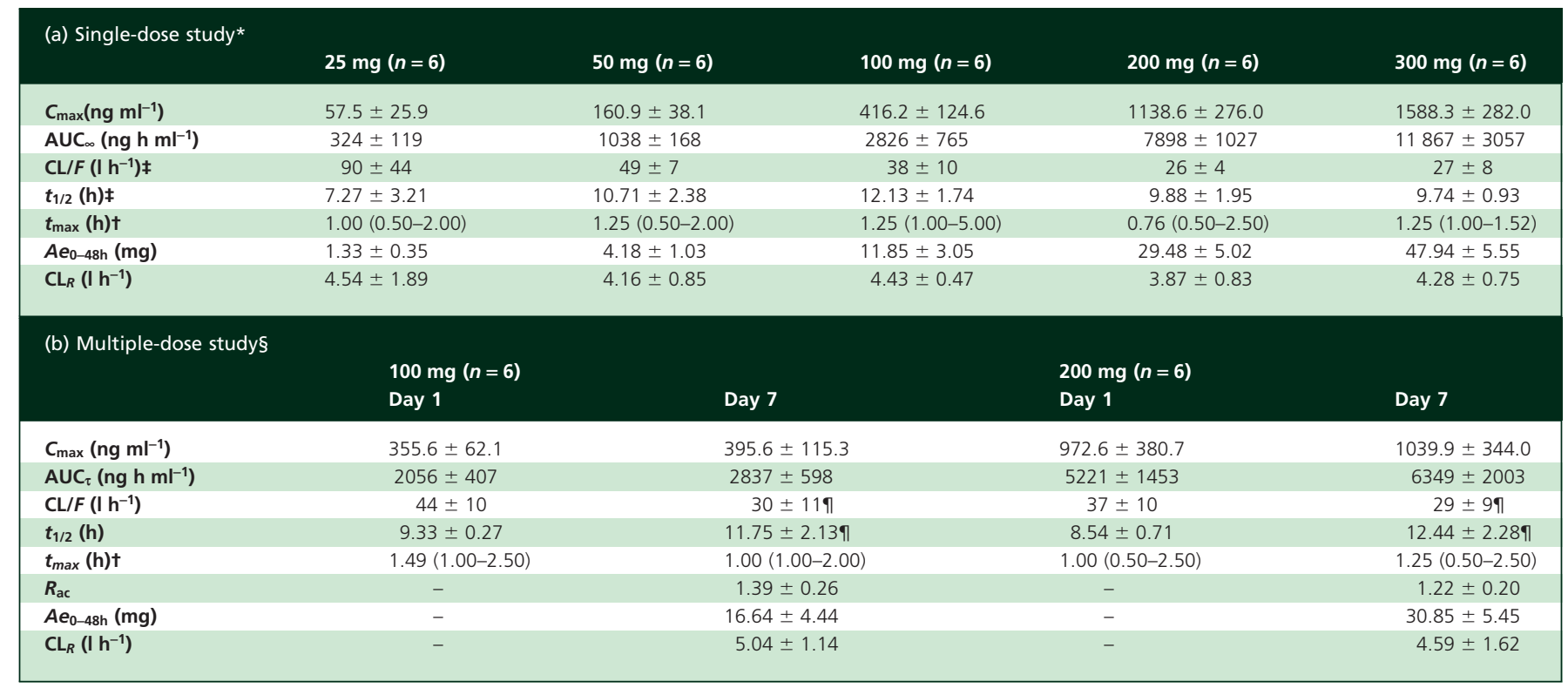

*Values are presented as the mean \pm standard deviation. $C_{\max }$, maximum plasma concentration; $A \cup C_{\infty}, A \cup C$ extrapolated to infinity; $C L / F(a p p a r e n t ~ c l e a r a n c e) ; ~ t / 12$, terminal half-life; $\mathrm{t}_{\max }$, time of maximum concentration; $\mathrm{Ae}_{0-48 \mathrm{~h}}$, amount excreted unchanged in urine during $0-48 \mathrm{~h} ; \mathrm{CL}_{\mathrm{R}}$, renal clearance. $\mathrm{t}_{\max }$, median and range are presented. $\neq \mathrm{P}<0.05$, comparison of values using the analysis of variance (ANOVA) among the dose groups. $\S$ Values are presented as the mean \pm standard deviation. $C_{\max }$, maximum plasma concentration; $A U C_{\tau}$, interval AUC ( $0-24 \mathrm{~h}$ at day 1 or day 7); CLF (apparent clearance); $\mathrm{t}_{1 / 2}$, terminal half-life; $\mathrm{t}_{\max }$, time of maximum concentration; $\mathrm{R}_{\mathrm{ac}}$ (accumulation Index), calculated as AUC $\tau_{\tau}$, ss (day 7)/AUC $\tau$ (day 1); Ae-48h, amount excreted unchanged in urine during day $70-48 \mathrm{~h} ; \mathrm{CL}_{\mathrm{R}}$, renal clearance. $\mathrm{qP}<0.05$, comparison of values using paired t-test compared with day 1 .
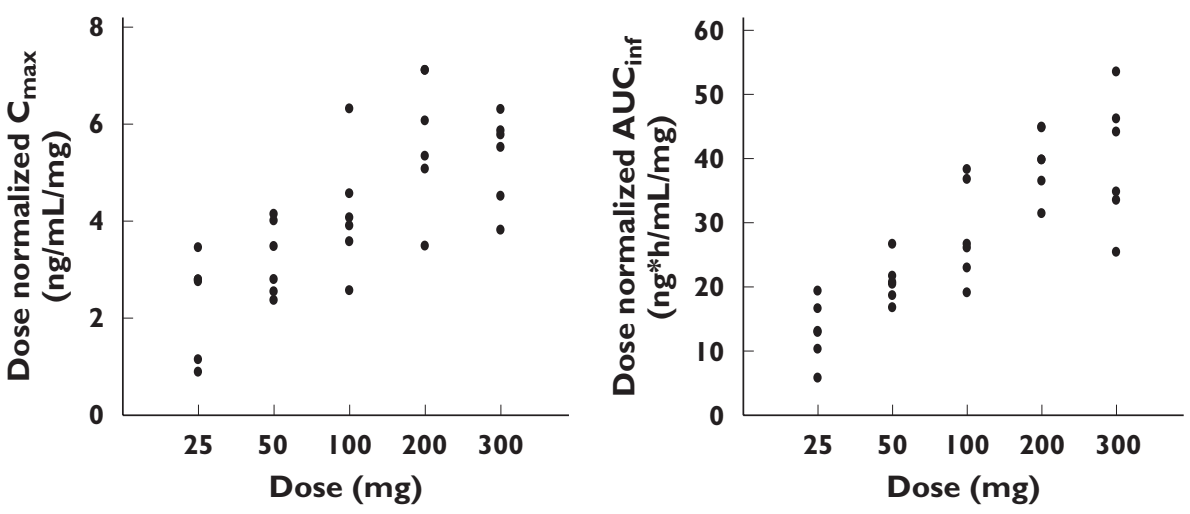

\section{Figure 3}

Distribution of dose-normalized $C_{\max }$ and $A U C_{\infty}$ values following single-dose administration. The values show supraproportional increases with dose $(P<0.0001)$

analysis [15]. The $C_{\max }$ and $A \cup C_{\infty}$ of vardenafil were also both increased to 2.2 -fold after doses of 10 and $20 \mathrm{mg}$, respectively [16]. This nonlinear pharmacokinetic characteristic implies that the drug's elimination is saturable. This might be due to saturation of the drug transporter or metabolic system and is recognized by a decrease in apparent clearance at higher doses [17]. This finding has also been shown in a preclinical study, in which the pharmacokinetics following single escalating doses of udenafil in rats revealed an increase in oral bioavailability relative to the administered amount of udenafil $\left(30 \mathrm{mg} \mathrm{kg}^{-1}, 38 \%\right.$; $50 \mathrm{mg} \mathrm{kg}^{-1}, 55.6 \%$; administered amount, oral bioavailability, respectively) [18].

In the multiple-dose study, the half-life on day 7 was longer than in the single-dose study. This may be accounted for by differences in the PK-sampling time points [i.e. the additional $48 \mathrm{~h}$ after the last (seventh) dosing in the multiple-dose study]. Udenafil exhibited a longer half-life (7-12 h) than sildenafil (half-life $4 \mathrm{~h}$ ) [10]. The longer half-life means a longer exposure of the human 
body to the PDE-5 inhibitor, and this might result in a longer duration of effect. The median $t_{\max }$ of udenafil was $1 \mathrm{~h}$ after dosing, and this is similar to that of sildenafil, implying that the onset of the udenafil effect would be as fast as that of sildenafil. However, the effects of the longer half-life and equal $t_{\max }$ of udenafil should be further evaluated in the context of patient responses in later phase clinical trials (reports in submission).

The $I_{50}$ value (mean \pm SD) of udenafil was $8.25 \pm 2.90 \mathrm{nM}$ and sildenafil was $8.50 \pm 2.05 \mathrm{nM}$ in the PDE-5 of human platelets [11]. The oral bioavailability of udenafil has been calculated to be $38-56 \%$ in rats [18], and that of sildenafil to be $23-44 \%$ in rats [19]. Therefore, udenafil was expected to show a similar clinical dosage range compared with sildenafil. Based on these pharmacological findings and also the safety results of this study, further studies of udenafil in erectile dysfunction patients were conducted at dosages ranging from 100 to $200 \mathrm{mg}$. The efficacy and safety were confirmed for the same dose range (100-200 mg) in the following Phase III studies, and Korean regulatory authorities subsequently approved this dosage range for erectile dysfunction patients [20].

In summary, udenafil was found to be safe and welltolerated in normal healthy subjects. Although the AUC and $C_{\max }$ of udenafil increased supraproportionally with increasing dose on single administration, there was no significant drug accumulation upon multiple administrations. Based on these findings, the proposed dosing regimens and efficacy of udenafil were evaluated in further studies involving patients with erectile dysfunction.

\section{Competing Interests}

None to declare.

This study was sponsored by Dong-A Pharmaceutical Company, Korea (0202-088-011).

\section{REFERENCES}

1 Saigal CS, Wessells H, Pace J, Schonlau M, Wilt T. Predictors and prevalence of erectile dysfunction in a racially diverse population. Arch Intern Med 2006; 166: 207-12.

2 Lue TF. Erectile dysfunction. N Engl J Med 2000; 342: 1802-13.

3 Taher A, Meyer M, Stief CG, Jonas U, Forssmann WG. Cyclic nucleotide phosphodiesterase in human cavernous smooth muscle. World J Urol 1997; 15: 32-5.

4 Lue TF. Physiology of penile erection and pathophysiology of erectile dysfunction. In: Campbell-Walsh Urology, 9th edn, eds Wein AJ, Kavoussi LR, Novick AC, Partin AW, Peters CA. China: Saunders, 2007; 728-9.

5 Fink HA, MacDonald R, Rutks IR, Nelson DB, Wilt TJ. Sildenafil for male erectile dysfunction: a systematic review and meta-analysis. Arch Intern Med 2002; 162: 1349-60.
6 Raja SG, Nayak SH. Sildenafil: emerging cardiovascular indications. Ann Thorac Surg 2004; 78: 1496-506.

7 Corbin JD, Beasley A, Blount MA, Francis SH. High lung PDE5: a strong basis for treating pulmonary hypertension with PDE5 inhibitors. Biochem Biophys Res Commun 2005; 334: 930-8.

8 Vardi Y, Klein L, Nassar S, Sprecher E, Gruenwald I. Effects of sildenafil citrate (viagra) on blood pressure in normotensive and hypertensive men. Urology 2002; 59: 747-52.

9 Webb DJ, Freestone S, Allen MJ, Muirhead GJ. Sildenafil citrate and blood-pressure-lowering drugs: results of drug interaction studies with an organic nitrate and a calcium antagonist. Am J Cardiol 1999; 83: 21C-8C.

10 Viagra ${ }^{\circledR}$ (sildenafil citrate) prescribing information; Description, clinical pharmacology, adverse reactions. Pfizer Laboratories 2007. Available at: http://fda.gov/cder/foi/label/ 2007/0208955027161.pdf (last accessed: 27 February 2008).

11 Doh H, Shin CY, Son M, Ko Jl, Yoo M, Kim SH, Kim WB. Mechanism of erectogenic effect of the selective phosphodieterease type 5 inhihbitor, DA-8159. Arch Pharm Res 2002; 25: 873-8.

12 Salem EA, Kendirci M, Hellstrom WJ. Udenafil, a long-acting PDE5 inhibitor for erectile dysfunction. Curr Opin Invest Drugs 2006; 7: 661-9.

13 Shim HJ, Lee EJ, Jung YH, Kim SH, Kim SH, Yoo M, Kwon JW, Kim WB, Lee MG. Determination of a new phosphodiesterase $\mathrm{V}$ inhibitor, DA-8159, in plasma and urine by high-performance liquid chromatography. J Pharm Biomed Anal 2002; 30: 527-33.

14 Cho JY, Lim HS, Yu KS, Shim HJ, Jang IJ, Shin SG. Sensitive liquid chromatography assay with ultraviolet detection for a new phosphodiesterase inhibitor, DA-8159, in human plasma and urine. J Chromatogr B Anal Technol Biomed Life Sci 2003; 795: 179-86.

15 Nichols DJ, Muirhead GJ, Harness JA. Pharmacokinetics of sildenafil after single oral doses in healthy male subjects: absolute bioavailability, food effects and dose proportionality. Br J Clin Pharmacol 2002; 53: 5S-12S.

16 Klotz T, Sachse R, Heidrich A, Jockenhövel F, Rohde G, Wensing G, Horstmann R, Engelmann R. Vardenafil increases penile rigidity and tumescence in erectile dysfunction patients: a RigiScan and pharmacokinetic study. World J Urol 2001; 19: 32-9.

17 Undevia SD, Gomez-Abuin G, Ratain MJ. Pharmacokinetic variability of anticancer agents. Nat Rev Cancer 2005; 5: 447-58.

18 Shim HJ, Kim YC, Park KJ, Kim DS, Kwon JW, Kim WB, Lee MG. Pharmacokinetics of DA-8159, a new erectogenic, after intravenous and oral administration to rats: hepatic and intestinal first-pass effects. J Pharm Sci 2003; 92: 2185-95.

19 Walker DK, Ackland MJ, James GC, Muirhead GJ, Rance DJ, Wastall P, Wright PA. Pharmacokinetics and metabolism of sildenafil in mouse, rat, rabbit, dog and man. Xenobiotica 1999; 29: 297-310.

20 Dong-A Research Laboratories. Zydena ${ }^{\circledR}$ (udenafil), Investigator's brochure. August 2007. 